\title{
ARTICLE
}

\section{Analysis of Physical and Sensory Properties according to Sugar Types in Yugwa}

\author{
Hyung-Yoon Choi, Heeyoung Lee, Mi Jang, Sunhyun Park, \\ Jiyoun Jeong, You-Shin Shim, Jong-Chan Kim \\ Food Standard Research Center, Korea Food Research Institute, Jeollabuk-do 55365, Korea
}

Received: October 29, 2021

Revised: November 19, 2021

Accepted: November 30, 2021

*Corresponding author :

Jong-Chan Kim

Food Standard Research Center, Korea

Food Research Institute, Jeollabuk-do

55365, Korea.

Tel : +82-063-219-9155

E-mail : jckim@kfri.re.kr

Copyright $\odot 2021$ Resources Science Research Institute, Kongju National University. This is an Open Access article distributed under the terms of the Creative Commons Attribution Non-Commercial License (http:// creativecommons.org/licenses/by-nc/4.0) which permits unrestricted non-commercial use, distribution, and reproduction in any medium, provided the original work is properly cited.

\section{ORCID}

Hyung-Yoon Choi https://orcid.org/0000-0002-1882-3190

Heeyoung Lee https://orcid.org/0000-0001-6115-9179

Mi Jang

https://orcid.org/0000-0002-4847-9482

Sunhyun Park

https://orcid.org/0000-0002-5077-7454

Jiyoun Jeong

https://orcid.org/0000-0002-6439-8033

You-Shin Shim

https://orcid.org/0000-0002-5496-9672

Jong-Chan Kim

https://orcid.org/0000-0002-1535-4181

\begin{abstract}
Yugwa is a traditional food unique to Korea, and the manufacturing of yugwa is largely divided into two processes: making the bandaegi and coating the bandaegi with sugar. To control the yugwa quality and strengthen the market competitiveness, this study analyzed changes in physical properties during storage according to the type of sugar used in yugwa manufacturing and the temperature that the sugar is applied. Consumer preference was evaluated for 30 adult men and women using a 9-point scale for overall preference, uniformity of garnish, color brightness, sweetness, unpleasant smell, and texture. Physical property analysis measured physical changes during storage, based on the type of sugar used to coat the yugwa and the storage temperatures $\left(30^{\circ} \mathrm{C}\right.$ and $\left.4^{\circ} \mathrm{C}\right)$ over $5 \mathrm{wk}$. In the manufacture of starch syrup, it was easier to maintain the quality according to the storage period and to use starch syrup alone than starch syrup alone. In addition, the application of sugar at $100^{\circ} \mathrm{C}$ helps to maintain quality even though the storage period is increased.
\end{abstract}

Keywords

yugwa, Physical properties, Sensory quality, Sugar type, Storage temperature

\section{Introduction}

Yugwa is a traditional Korean food that has been passed down by our ancestors. yugwa is made by pulverizing glutinous rice, kneading it in alcohol, steaming, boiling, and mixing it to form a cracker, cutting it in various sizes, and frying it in oil to form the final product (National Agricultural Products Quality Management, 2020). Consumer demand for yugwa continues to increase, and research has been conducted to raise the popularity and consumer awareness of Korean sweets as part of the globalization of Korean food (Lee et al., 1987, 2012; Choi and Cho, 2008). However, research on manufacturing methods to secure competitiveness in the yugwa market is insufficient. The process of making yugwa is largely divided into producing the bandaegi and coating the bandaegi with a mixture of grain syrup, honey, and starch syrup. The quality characteristics of the product differ depending on the sugar used in the coating process. The ancestral recipe uses grain syrup; however, owing to changes in modern people's tastebuds and manufacturing cost, starch syrup is often used nowadays.

Sugar is applied to the bandaegi after the solution is heated and cooled to a specific temperature, and the quality characteristics of the product vary depending on the temperature of the syrup at application. Currently, producers usually apply sugar between $80^{\circ} \mathrm{C}$ and $100^{\circ} \mathrm{C}$, but there is no research or data to show which temperature is preferred. The purpose of this study was to evaluate the use of syrup (grain syrup, starch syrup, or a mixture of the two) and 
consumer preferences according to the application temperature of the syrup and storage temperature in order to revitalize the yugwa industry and to suggest ways to enhance market competitiveness.

\section{Materials and Methods}

\section{Sample preparation}

Yugwa was produced by a domestic yugwa producer, and test groups were prepared by dividing the yugwa on the basis of different types of sugar used (grain syrup, starch syrup, and mix of grain and starch syrup) and also the temperatures that the sugar was applied $\left(80^{\circ} \mathrm{C}\right.$ and $\left.100^{\circ} \mathrm{C}\right)$ (Table 1).

\section{Consumer preference evaluation}

Consumer preference evaluations were conducted on 30 men and women between 20 and 50 years of age in Jeollabuk-do, and evaluations were made based on the questionnaire in Table 2 using a 9-point scale method in Fig. 1. To evaluate consumer preference according to the type of sugar applied (process 1,2, and 3; Table 1), only the sugar application temperature of $80^{\circ} \mathrm{C}$ was considered.

\section{Physical property test}

To determine the product storage characteristics (type of sugar and sugar temperature at application), the physical properties of the final product were analyzed at 1 wk interval during storage at $30^{\circ} \mathrm{C}$ (room temperature) and $4^{\circ} \mathrm{C}$ (refrigeration temperature) for $5 \mathrm{wk}$. For the analysis, more than 10 samples were used for each treatment. Physical property analysis was performed using a texture analyzer (TA1, Lloyd, USA) equipped with a $25 \mathrm{~mm}$ cylinder probe, and the sample was measured according to the following conditions: pretest speed $2.0 \mathrm{~mm} / \mathrm{s}$,

Table 1. Preparation of yugwa samples

\begin{tabular}{|c|c|c|}
\hline Process & Mixing ratio & Application temperature of sugar \\
\hline 2 & Glutinous rice $83 \%$, starch syrup $15 \%$, soybean oil $2 \%$ & $80^{\circ} \mathrm{C}$ \\
\hline 3 & Glutinous rice $83 \%$, grain syrup $10 \%$, starch syrup $5 \%$, soybean oil $2 \%$ & $80^{\circ} \mathrm{C}$ \\
\hline 4 & Glutinous rice $83 \%$, grain syrup $15 \%$, soybean oil $2 \%$ & $100^{\circ} \mathrm{C}$ \\
\hline
\end{tabular}

Table 2. Yugwa consumer preference evaluation panel

\begin{tabular}{ccccccc}
\hline Category & $20 \mathrm{~s}$ & $30 \mathrm{~s}$ & $40 \mathrm{~s}$ & $50 \mathrm{~s}$ & Total & Remarks \\
\hline $\begin{array}{c}\text { Number of } \\
\text { individuals (名) }\end{array}$ & 8 & 20 & 3 & 4 & 30 & Male/female ratio \\
Ratio (\%) & 22.9 & 57.1 & 8.6 & 11.4 & 100 & $50: 50$ \\
\hline
\end{tabular}


(1) Overall preferences

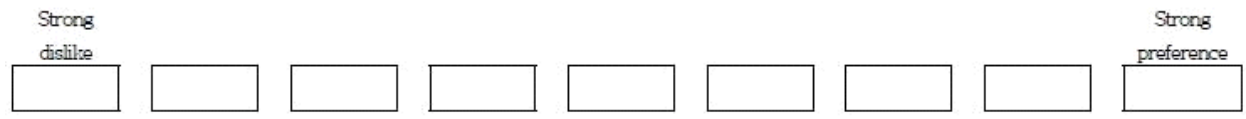

(2) Uniformity of garnish (popped rice)

Not uniform

Not unifor
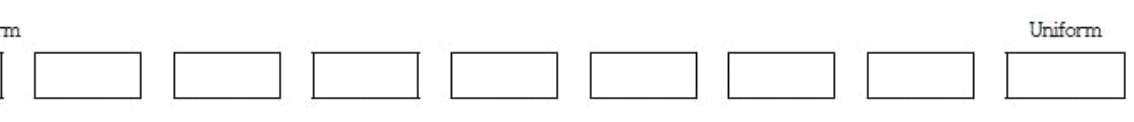

(3) Color brightness

\section{Dark}

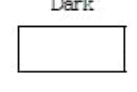

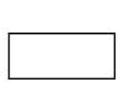
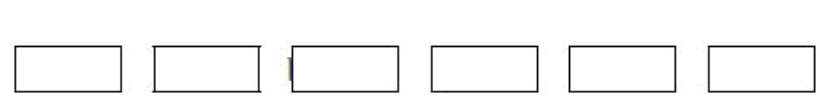

Bright

(4) Sweetness
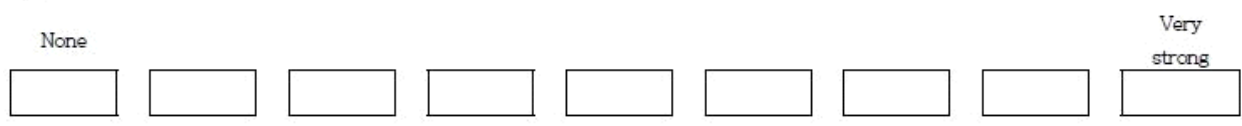

(5) Taste and scents

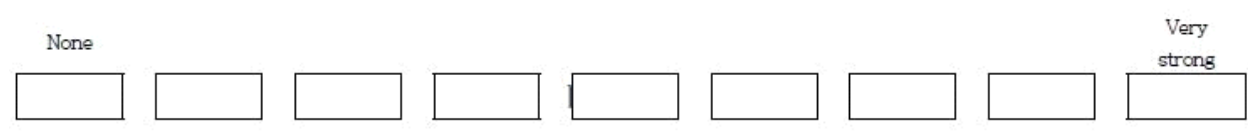

(6) Degree of chewiness (texture)
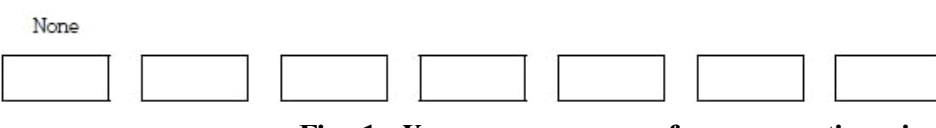

Fig. 1. Yugwa consumer preference questionnaire

posttest speed $5.0 \mathrm{~mm} / \mathrm{s}$, maximum load, $2 \mathrm{~kg}$; and head speed $2.0 \mathrm{~mm}$.

\section{Statistical analysis}

The data obtained were statistically analyzed using Minitab (version 14 for Windows, Penn State University, USA), and the significance test for the average value was verified at $5 \%$ level using analysis of variance and Duncan's multiple range test.

\section{Results and Discussion}

\section{Consumer preference evaluation}

The overall preference was significantly higher for starch syrup than that for grain syrup; however, no significant difference was observed in the overall preference for mixed starch syrup and grain syrup (Table 3). In the case of garnish attachment uniformity, there was no significant difference between the starch syrup alone and mixed grain syrup and starch syrup, but when manufactured using only grain syrup, the garnish attachment uniformity was significantly reduced. The brightness of the final product color was highest when only starch syrup was used, followed by a mixture of grain syrup and starch syrup, and a significantly lower brightness was 
Table 3. Consumer preference results

\begin{tabular}{cccccc}
\hline Category & Overall & $\begin{array}{c}\text { Uniformity of } \\
\text { garnish attachment }\end{array}$ & Brightness of color & Sweetness & Taste/scent \\
\hline $\begin{array}{c}\text { Starch syrup } \\
\text { Grain syrup }+ \\
\text { starch syrup }\end{array}$ & $4.857 \mathrm{a}$ & $5.343 \mathrm{a}$ & $5.286 \mathrm{a}$ & $3.914 \mathrm{a}$ & $2.657 \mathrm{a}$ \\
$\begin{array}{c}\text { Grain Syrup } \\
\text { Pr }>\text { F(Model) }\end{array}$ & $4.029 \mathrm{~b}$ & $4.200 \mathrm{~b}$ & $3.371 \mathrm{c}$ & $3.600 \mathrm{a}$ & $3.000 \mathrm{a}$ \\
\hline
\end{tabular}

observed when only grain syrup was used. No significant differences in consumer preferences were observed in the type of sugar used, sweetness, taste, or smell. As for the texture, the degree of acquisition was significantly higher for starch syrup alone and mixed starch syrup and grain syrup. Considering the results of consumer preference, there was no significant difference between sweetness and taste depending on the type of sugar (including both alone and mixed syrups); however, when starch syrup alone was used, the overall preference, color brightness, and textural preference were found to be better. We concluded that utilizing the appropriate amount of mixed syrup when manufacturing yugwa is recommended to improve consumer preferences, as well as quality control.

\section{Physical property test}

The physical properties of each treatment process were analyzed according to the storage conditions, and changes in physical properties among samples were observed as the low period increased when manufactured using grain syrup alone. Changes in physical properties among samples according to the storage condition were also observed (Fig. 2 11). The physical properties were analyzed based on storage length and according to the temperature at which the sugar is applied. In both grain syrup and starch syrup, less physical property changes were observed when sugar was applied at $100^{\circ} \mathrm{C}$. Taken together, the quality of the product canis be easily maintained by using starch syrup at $100^{\circ} \mathrm{C}$ during application. 


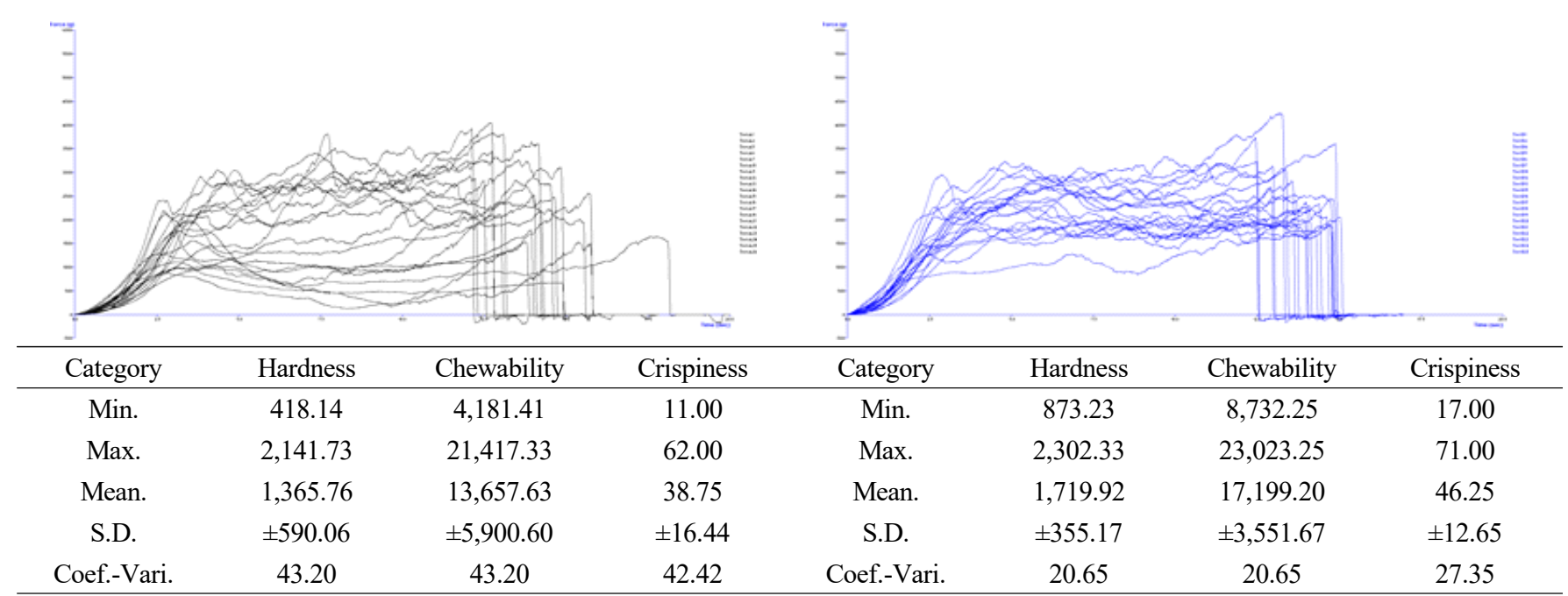

(a) $<$ Grain syrup at $100^{\circ} \mathrm{C}>$

(b) $<$ Starch syrup at $100^{\circ} \mathrm{C}>$

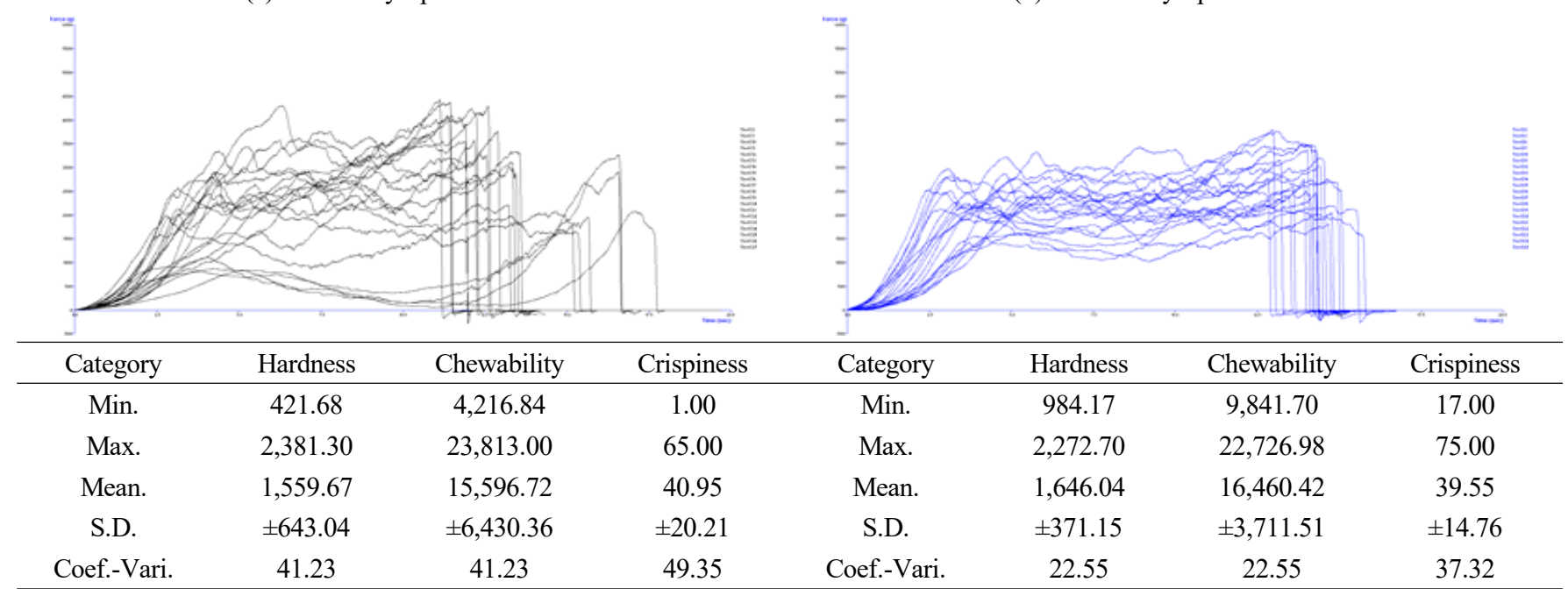

(c) $<$ Grain syrup at $80^{\circ} \mathrm{C}>$

(d) $<$ Starch syrup at $80^{\circ} \mathrm{C}>$

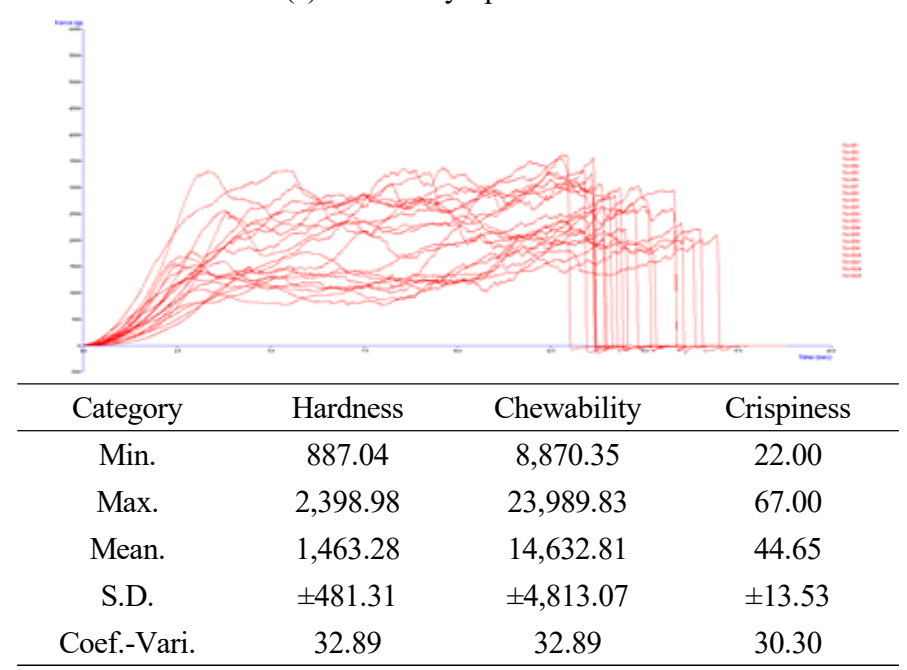

(d) $<$ Grain syrup + starch syrup at $100^{\circ} \mathrm{C}>$

Fig. 2. Week 1 results at $30^{\circ} \mathrm{C}$ storage 


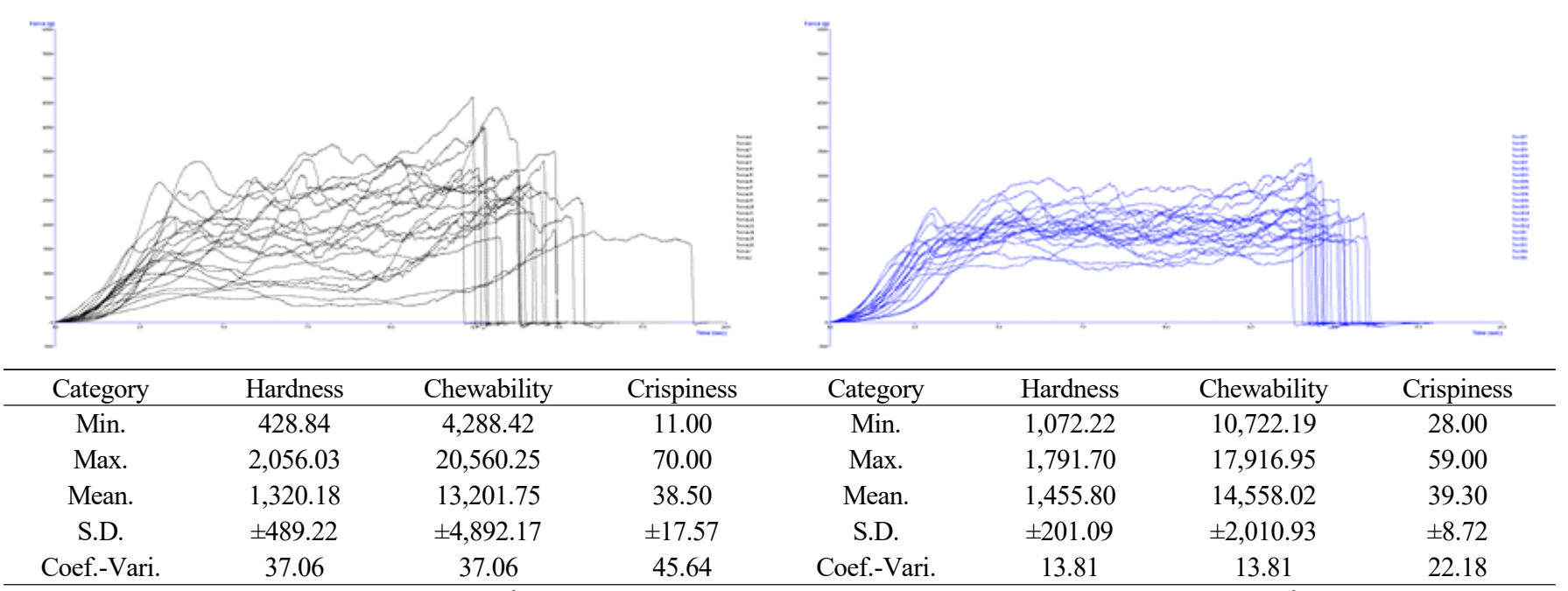

(a) $<$ Grain syrup at $100^{\circ} \mathrm{C}>$

(b) $<$ Starch syrup at $100^{\circ} \mathrm{C}>$

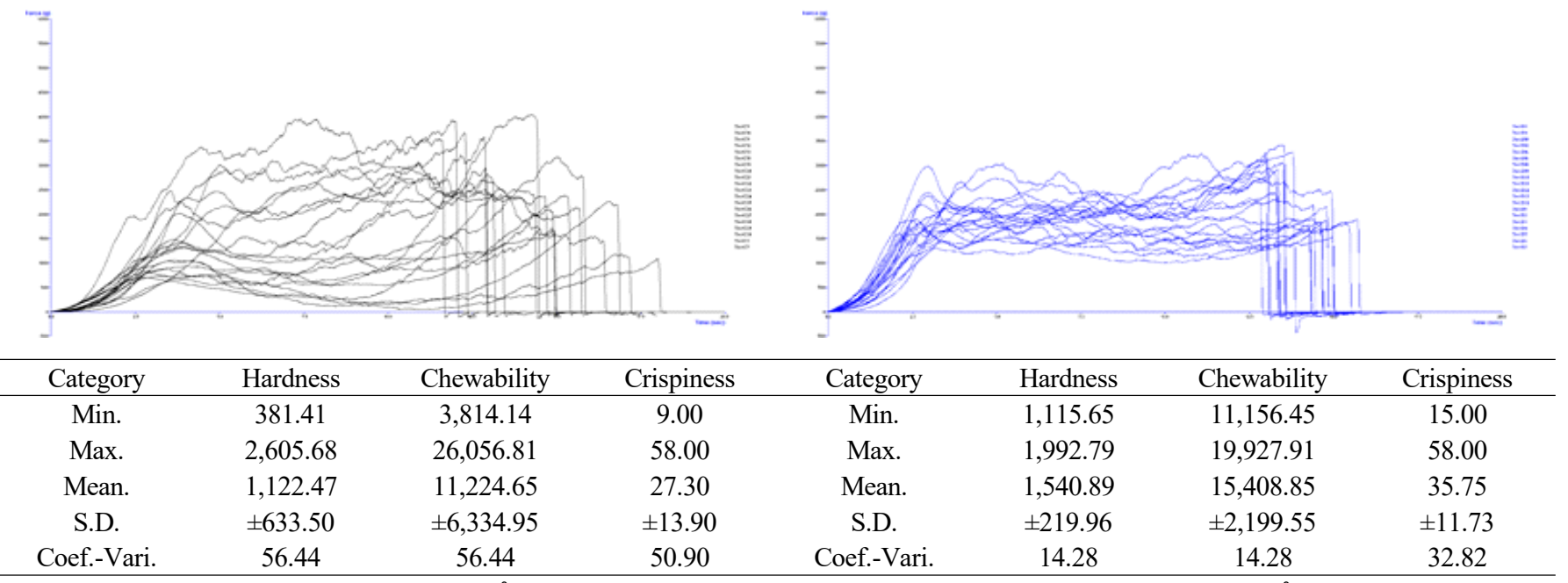

(c) $<$ Grain syrup at $80^{\circ} \mathrm{C}>$

(d) $<$ Starch syrup at $80^{\circ} \mathrm{C}>$

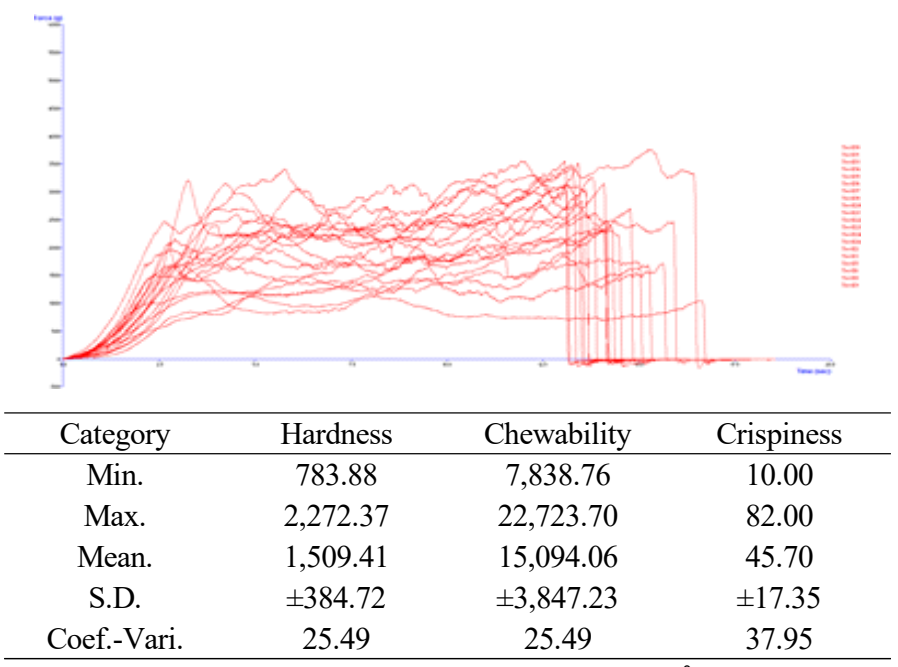

(e) $<$ Grain syrup + starch syrup at $100^{\circ} \mathrm{C}>$

Fig. 3. Week 2 results at $30^{\circ} \mathrm{C}$ storage 


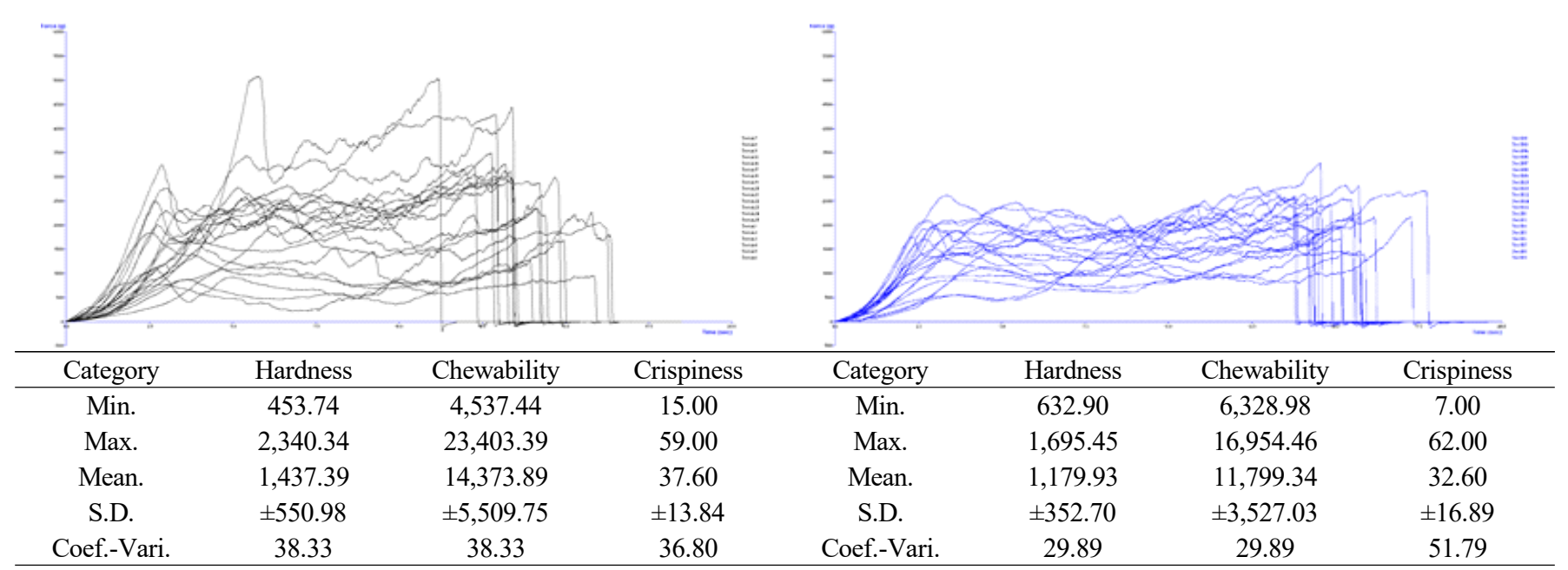

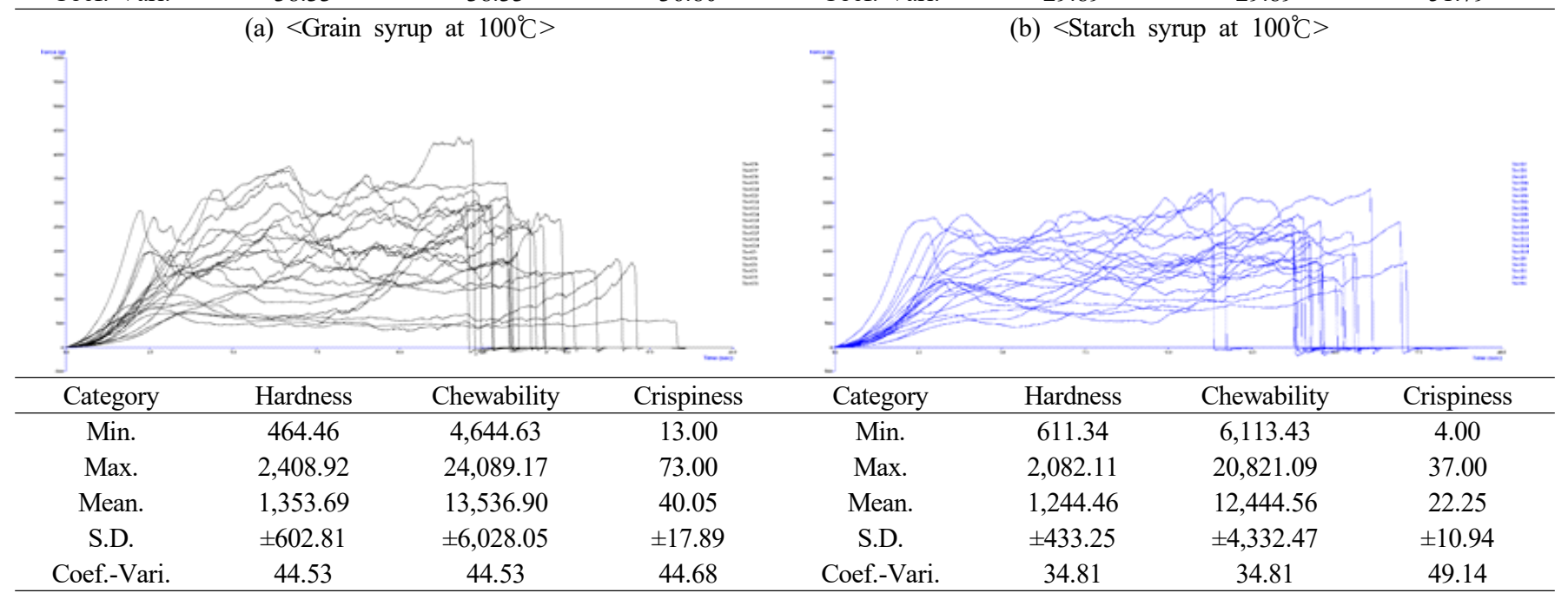

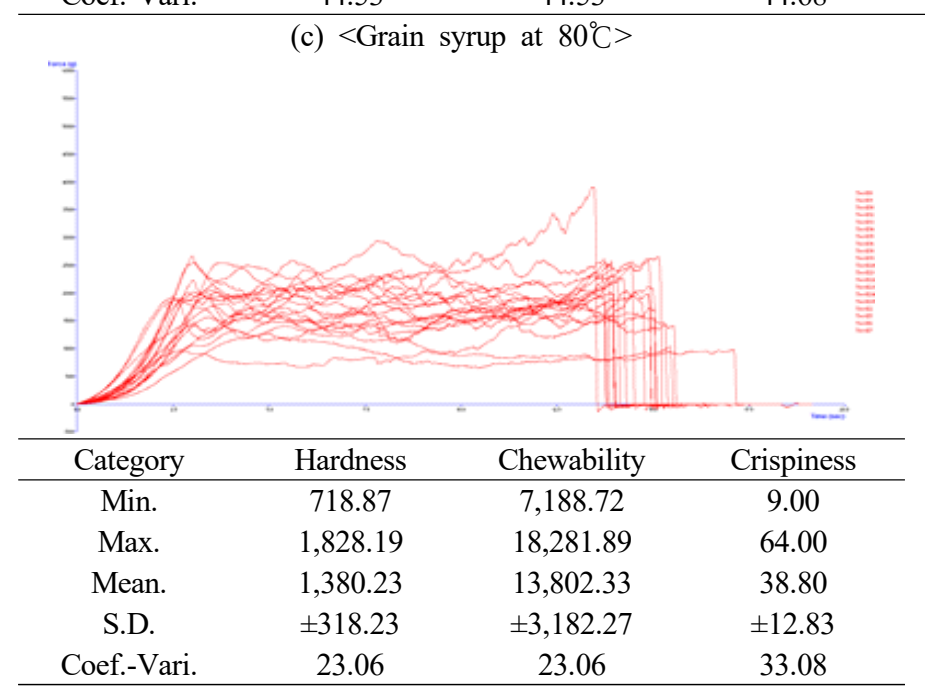

(e) $<$ Grain syrup + starch syrup at $100^{\circ} \mathrm{C}>$

(d) $<$ Starch syrup at $80^{\circ} \mathrm{C}>$

Fig. 4. Week 3 results at $30^{\circ} \mathrm{C}$ storage 


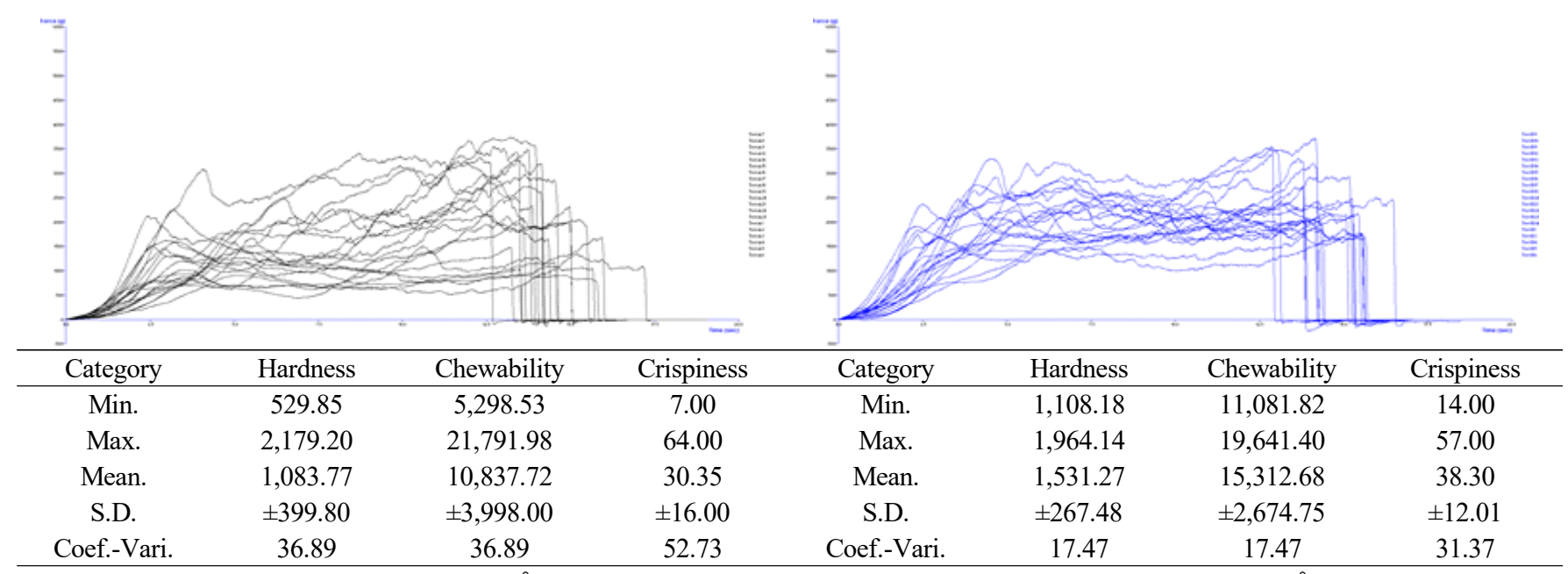

(a) $<$ Grain syrup at $100^{\circ} \mathrm{C}>$

(b) $<$ Starch syrup at $100^{\circ} \mathrm{C}>$
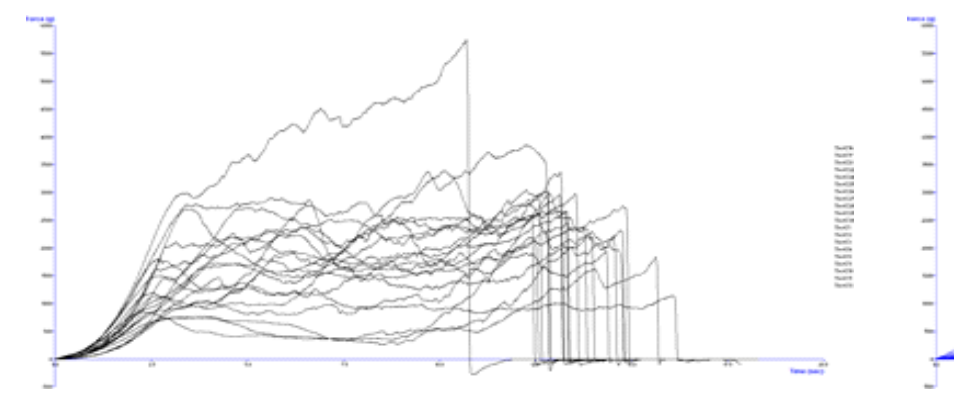

\begin{tabular}{cccccccc}
\hline Category & Hardness & Chewability & Crispiness & Category & Hardness & Chewability & Crispiness \\
\hline Min. & 438.80 & $4,387.97$ & 13.00 & Min. & 588.68 & $5,886.80$ & 7.00 \\
Max. & $3,103.60$ & $31,035.95$ & 65.00 & Max. & $1,495.51$ & $14,955.08$ & 58.00 \\
Mean. & $1,349.30$ & $13,492.96$ & 37.25 & Mean. & $1,107.44$ & $11,074.36$ & 27.25 \\
S.D. & \pm 615.86 & $\pm 6,158.56$ & \pm 15.05 & S.D. & \pm 227.60 & $\pm 2,275.96$ & \pm 12.54 \\
Coef.-Vari. & 45.64 & 45.64 & 40.39 & Coef.-Vari. & 20.55 & 20.55 & 46.02 \\
\hline
\end{tabular}

(c) $<$ Grain syrup at $80^{\circ} \mathrm{C}>$

(d) $<$ Starch syrup at $80^{\circ} \mathrm{C}>$

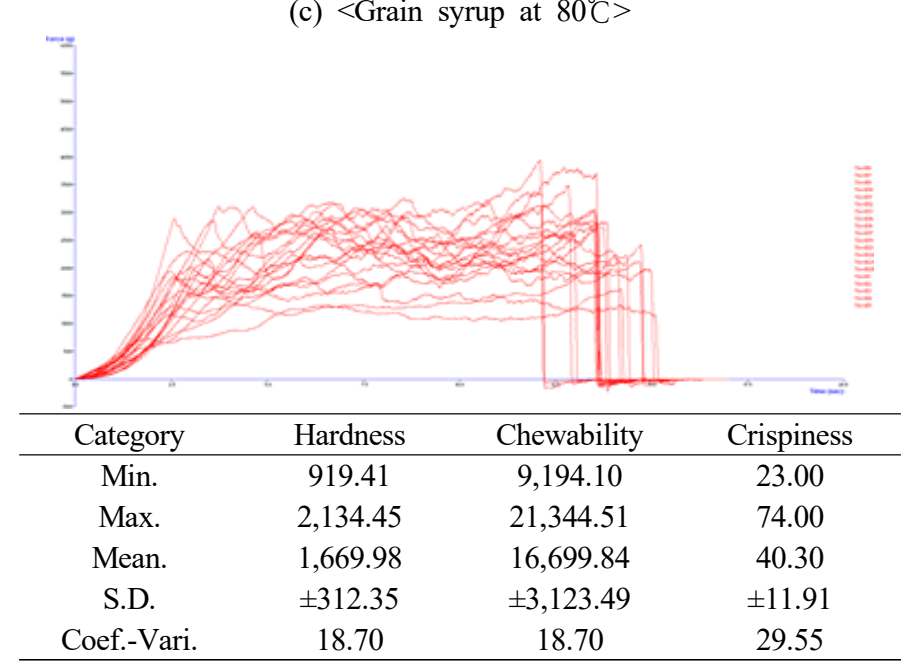

(e) $<$ Grain syrup + starch syrup at $100^{\circ} \mathrm{C}>$

Fig. 5. Week 4 results at $30^{\circ} \mathrm{C}$ storage 


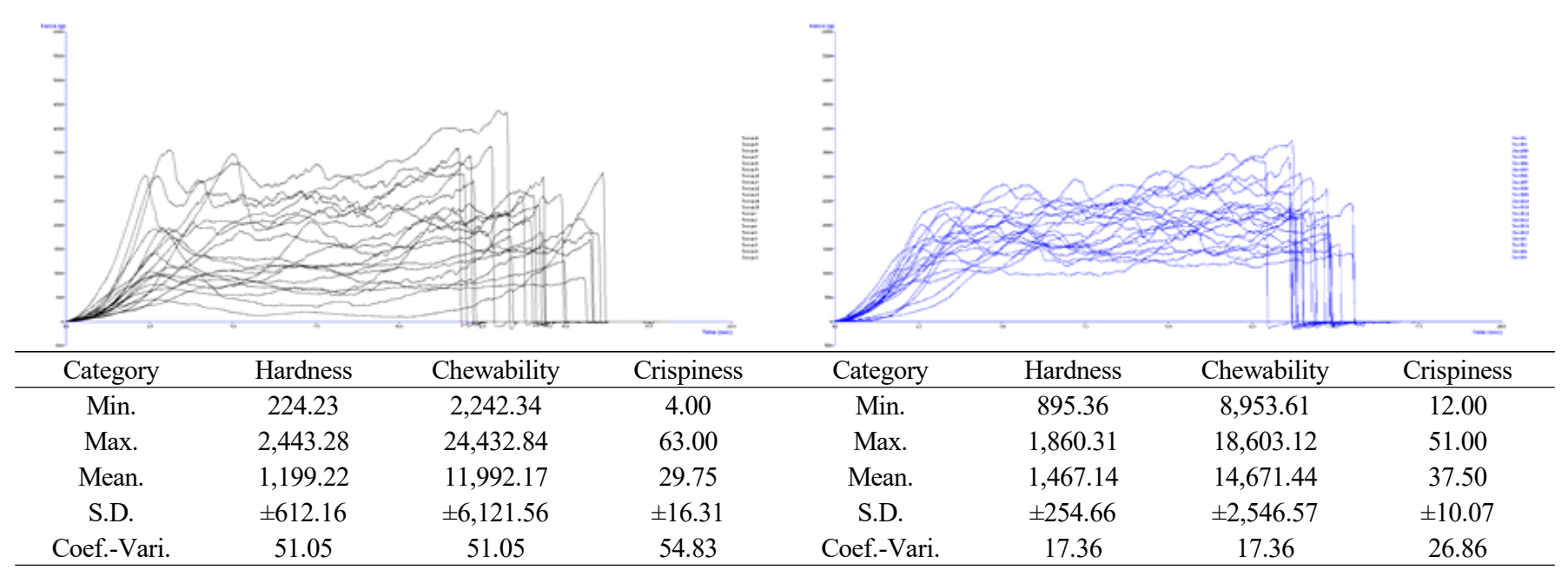

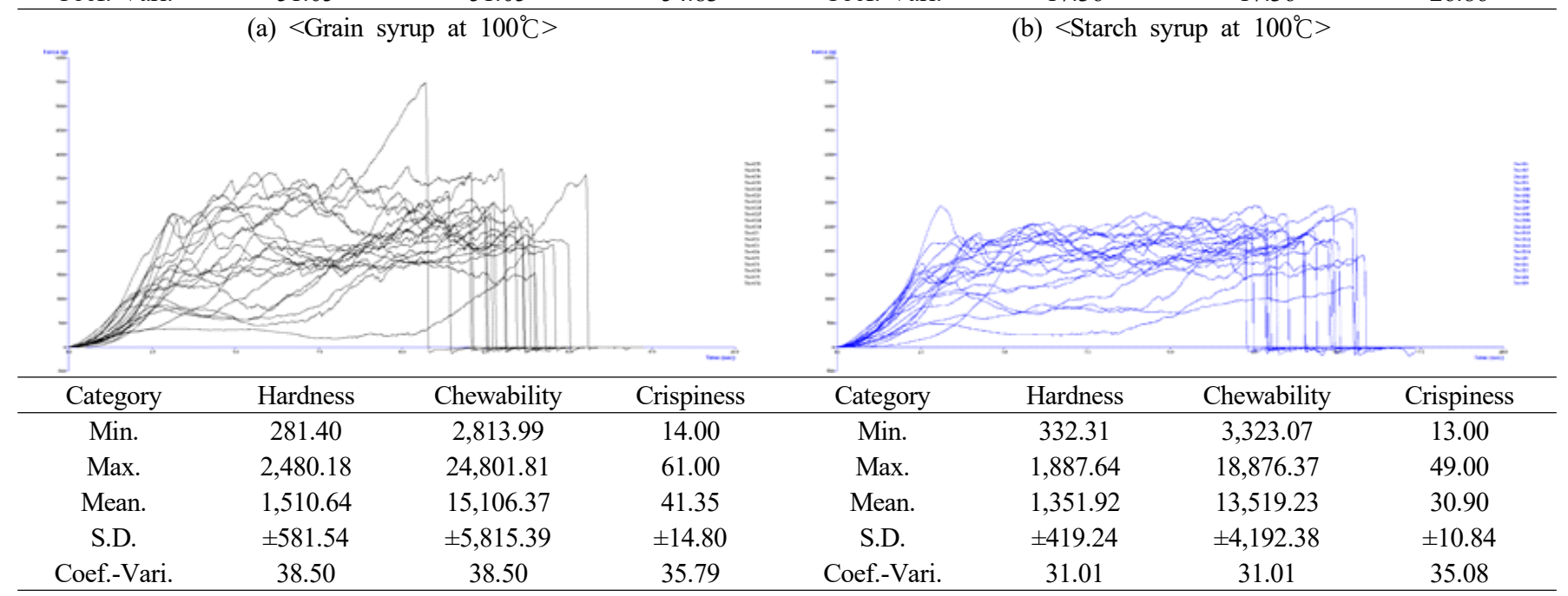

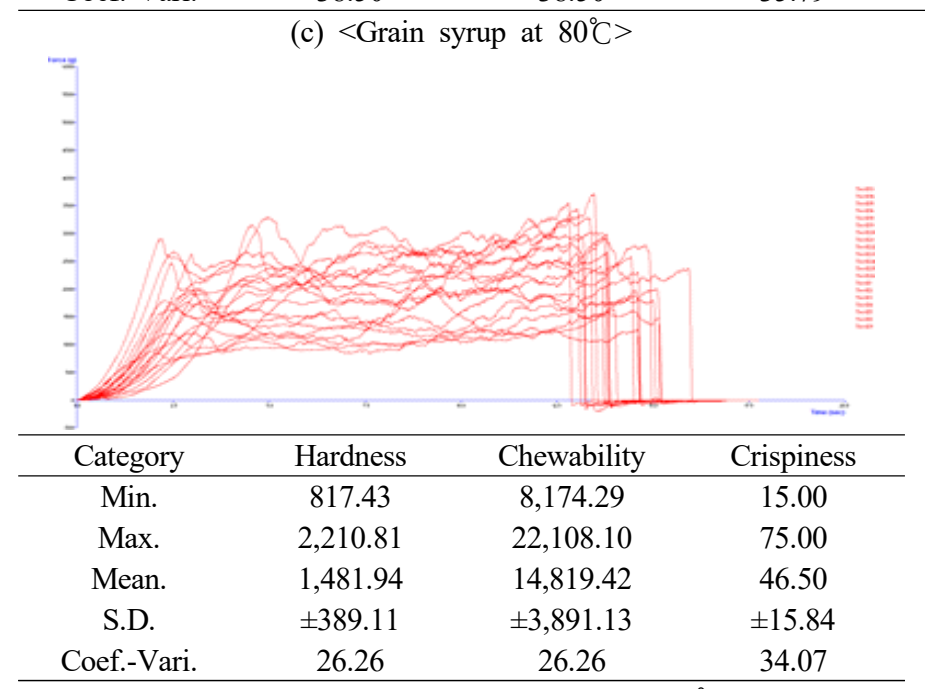

(e) $<$ Grain syrup + starch syrup at $100^{\circ} \mathrm{C}>$

(d) $<$ Starch syrup at $80^{\circ} \mathrm{C}>$

Fig. 6. Week 5 results at $30^{\circ} \mathrm{C}$ storage 


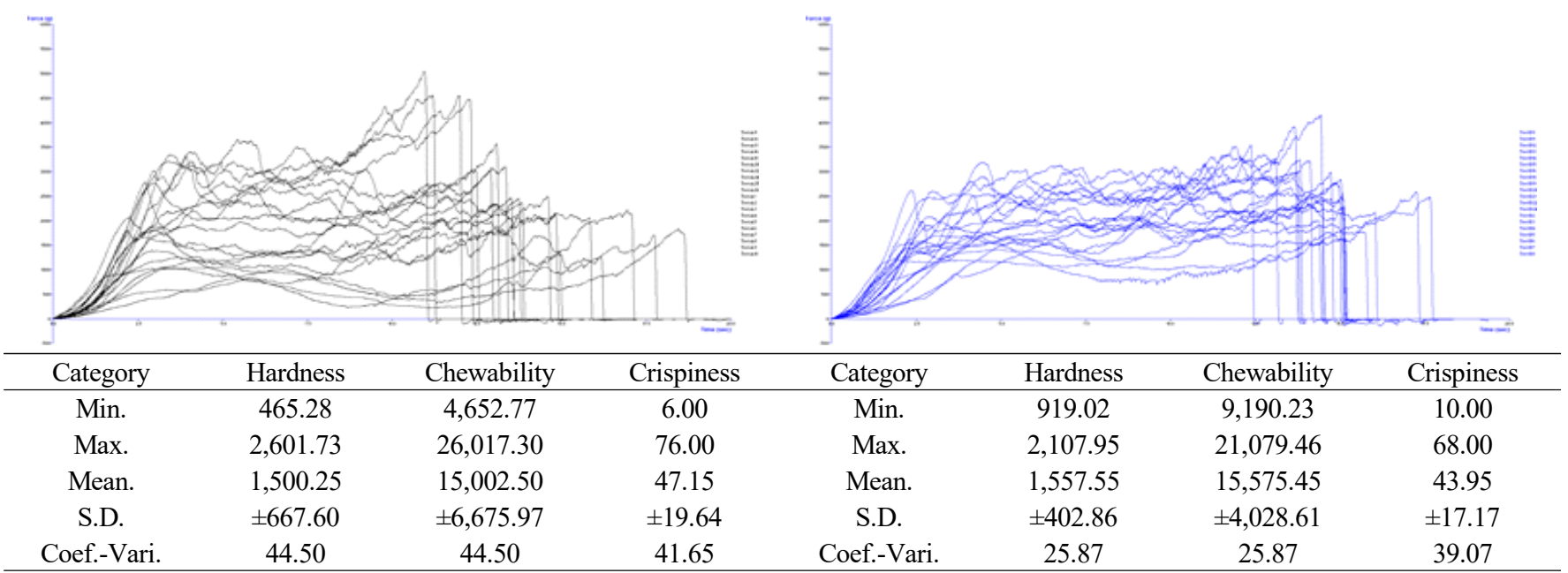

(a) $<$ Grain syrup at $100^{\circ} \mathrm{C}>$

(b) $<$ Starch syrup at $100^{\circ} \mathrm{C}>$

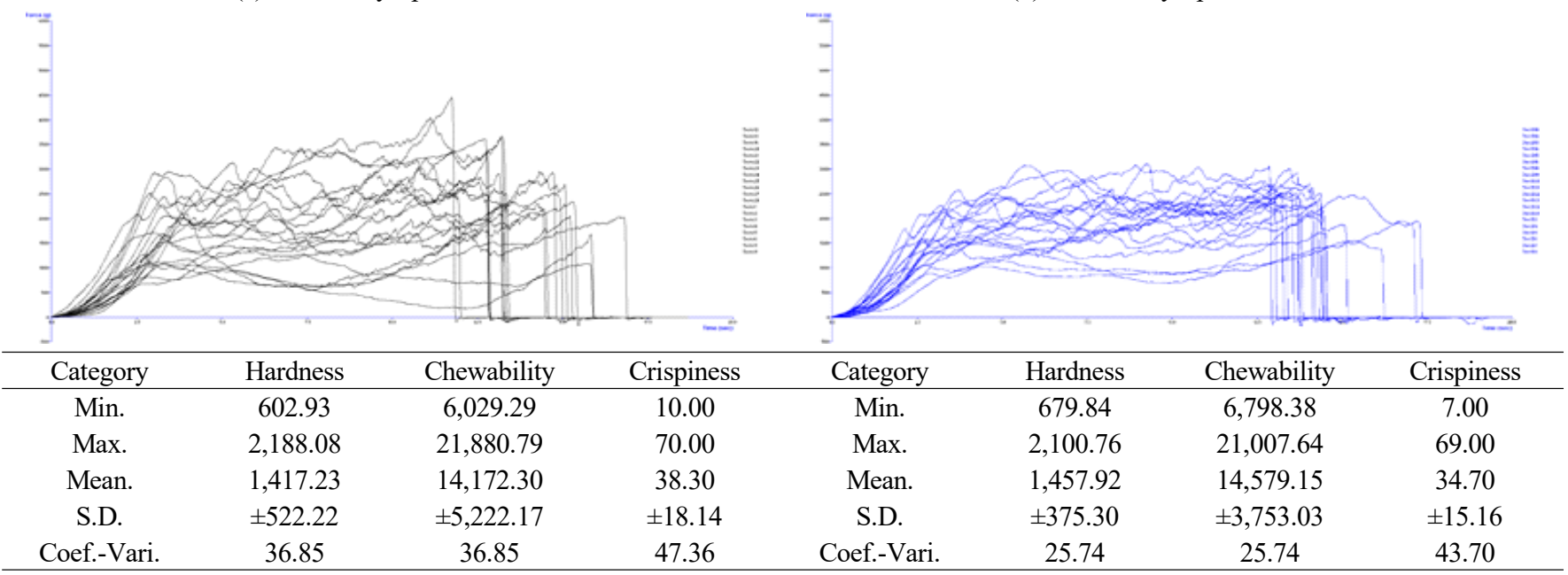

(c) $<$ Grain syrup at $80^{\circ} \mathrm{C}>$

(d) $<$ Starch syrup at $80^{\circ} \mathrm{C}>$

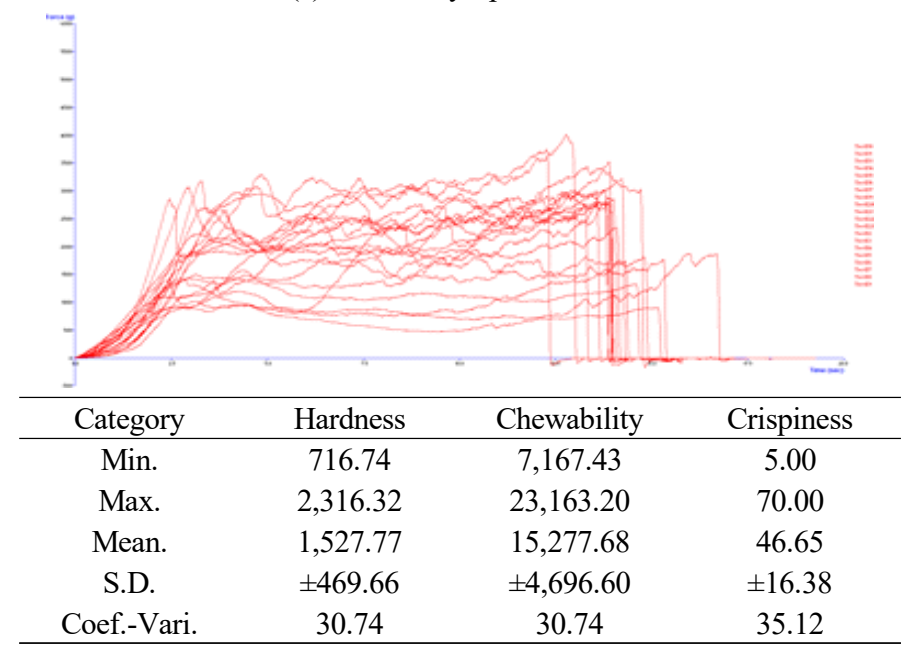

(e) $<$ Grain syrup + starch syrup at $100^{\circ} \mathrm{C}>$

Fig. 7. Week 1 results at $4^{\circ} \mathrm{C}$ storage 


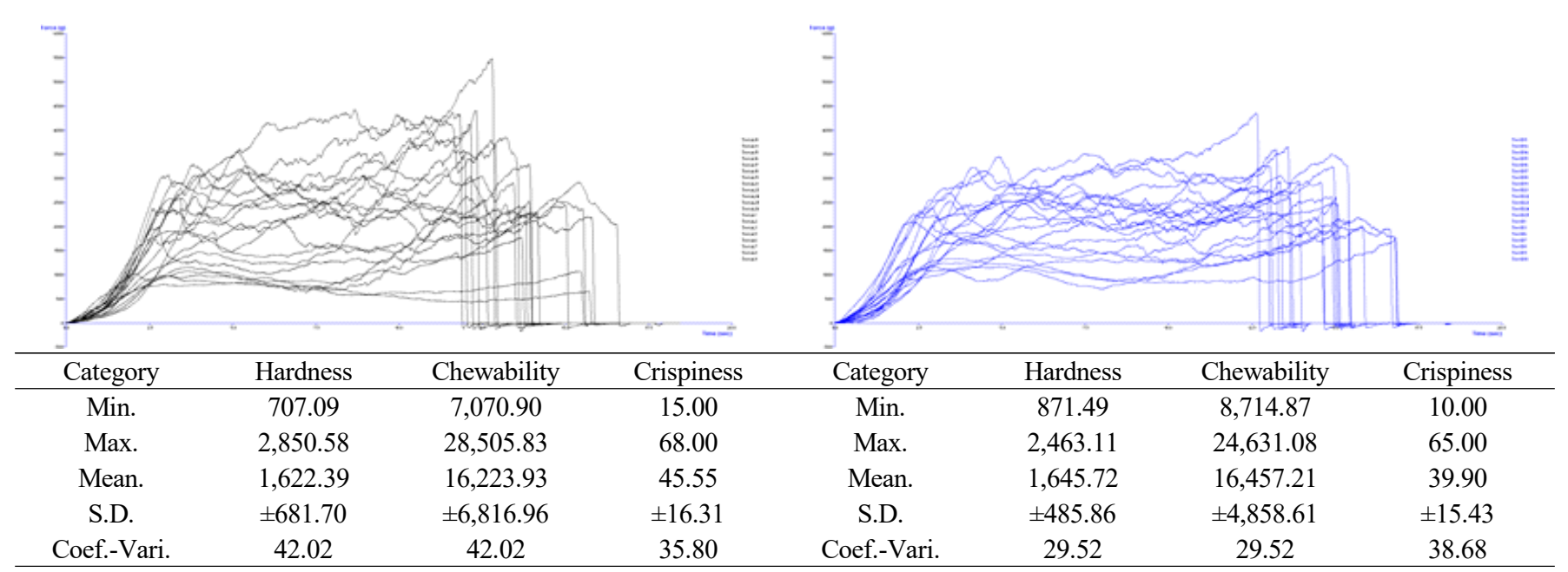

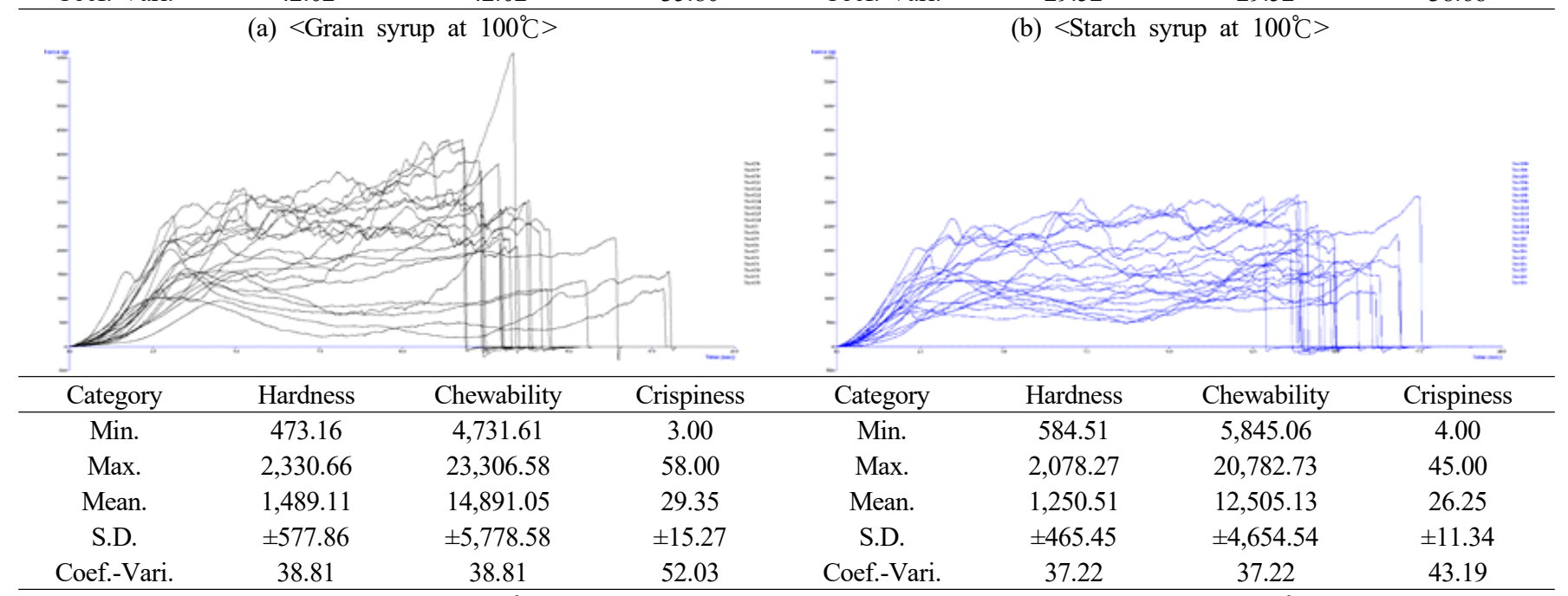

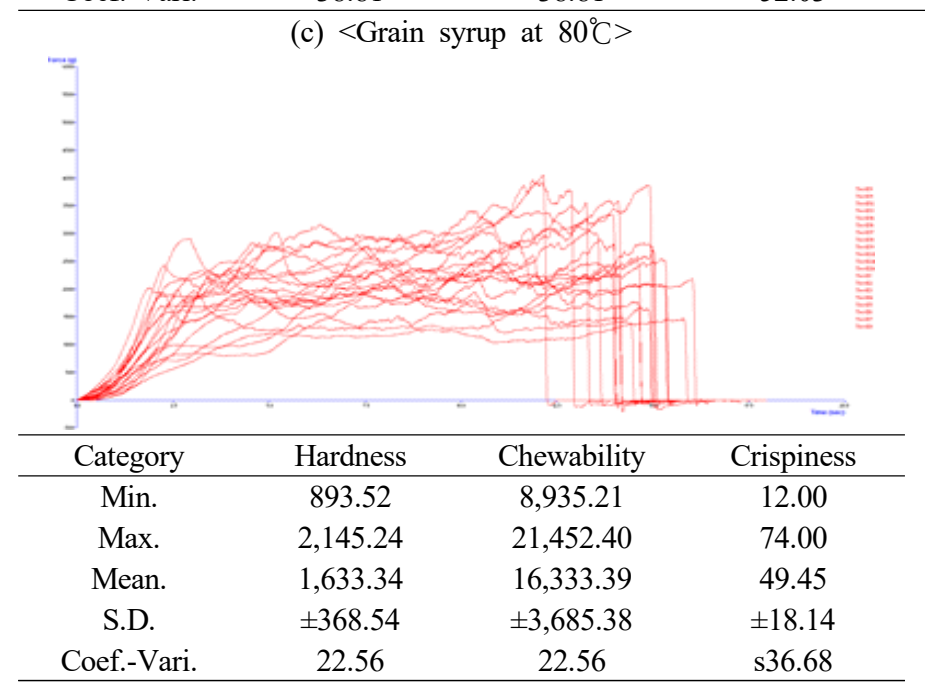

(d) $<$ Starch syrup at $80^{\circ} \mathrm{C}>$

(e) $<$ Grain syrup + starch syrup at $100^{\circ} \mathrm{C}>$

Fig. 8. Week 2 results at $4^{\circ} \mathrm{C}$ storage 

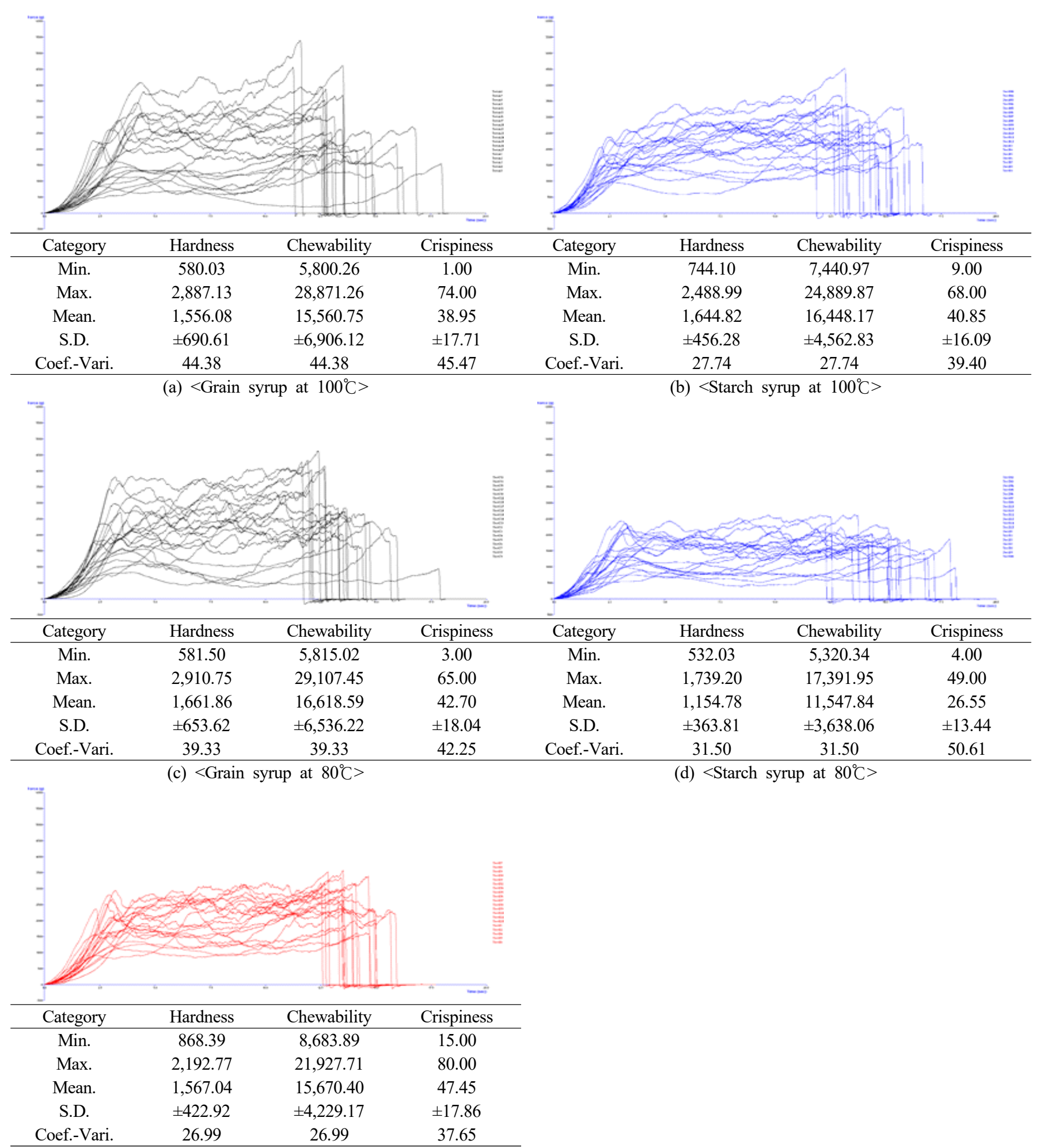

(e) $<$ Grain syrup + starch syrup at $100^{\circ} \mathrm{C}>$

Fig. 9. Week 3 results at $4^{\circ} \mathrm{C}$ storage 


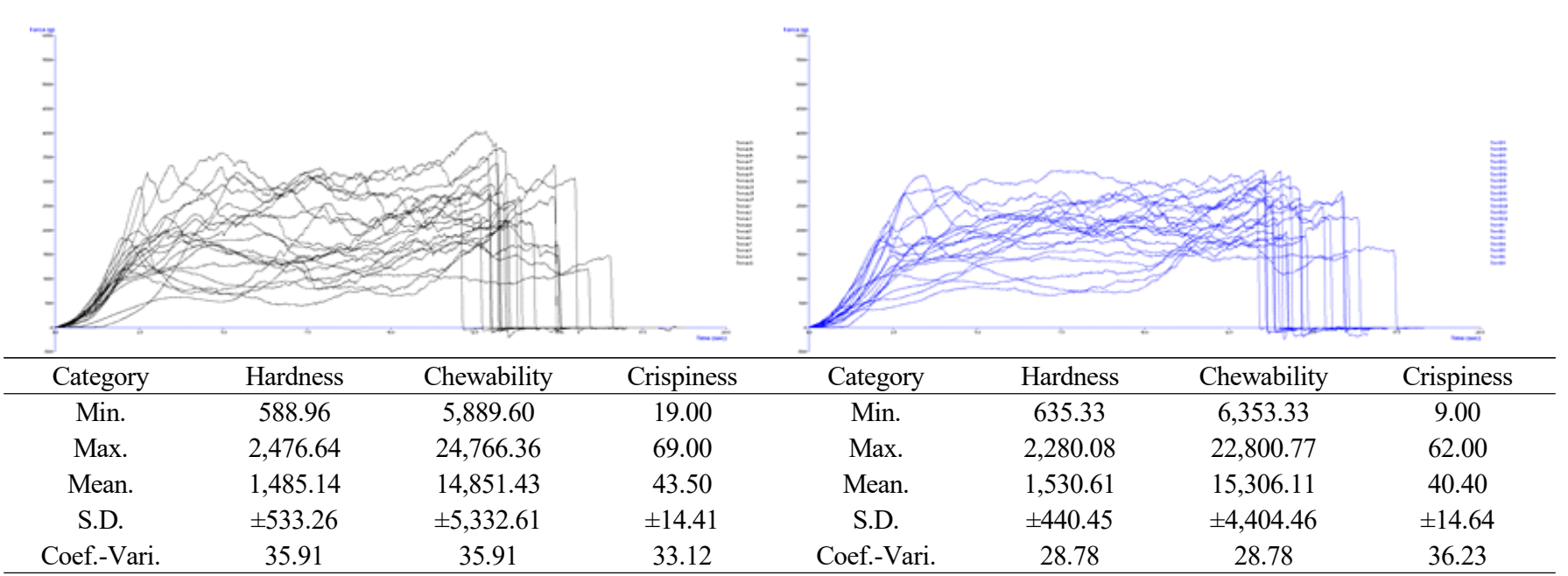

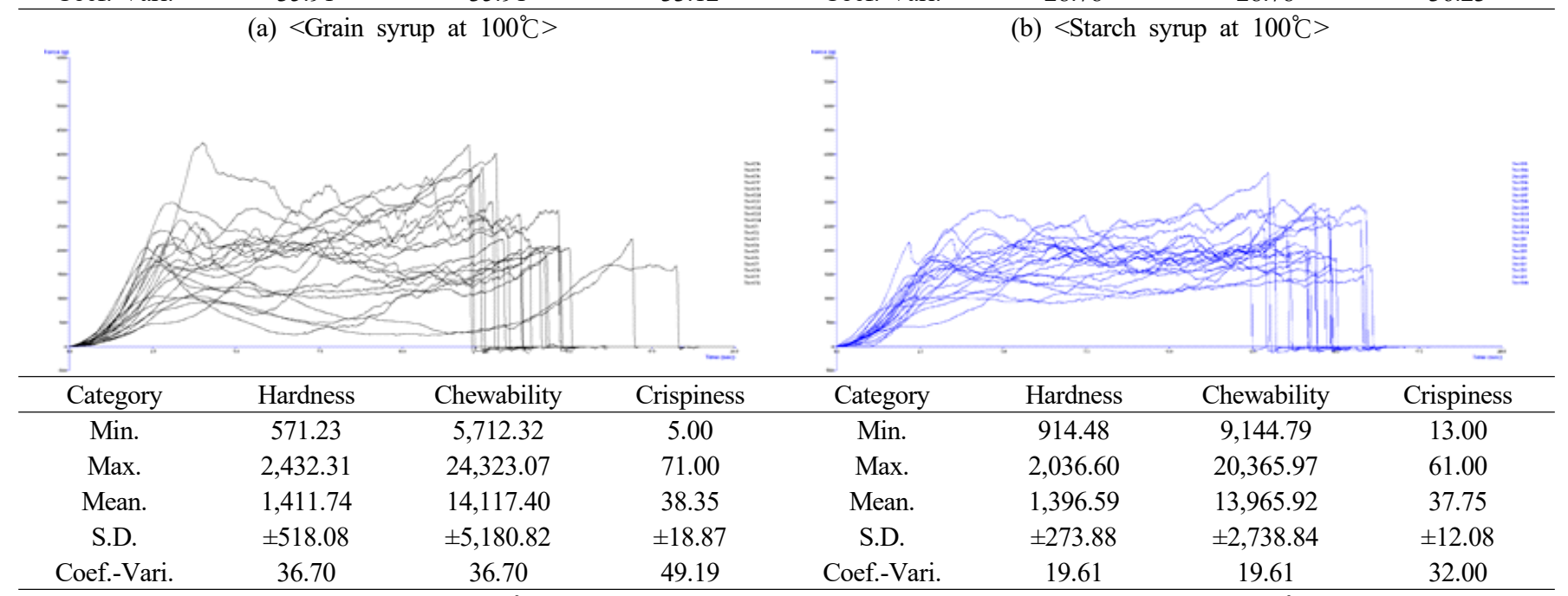

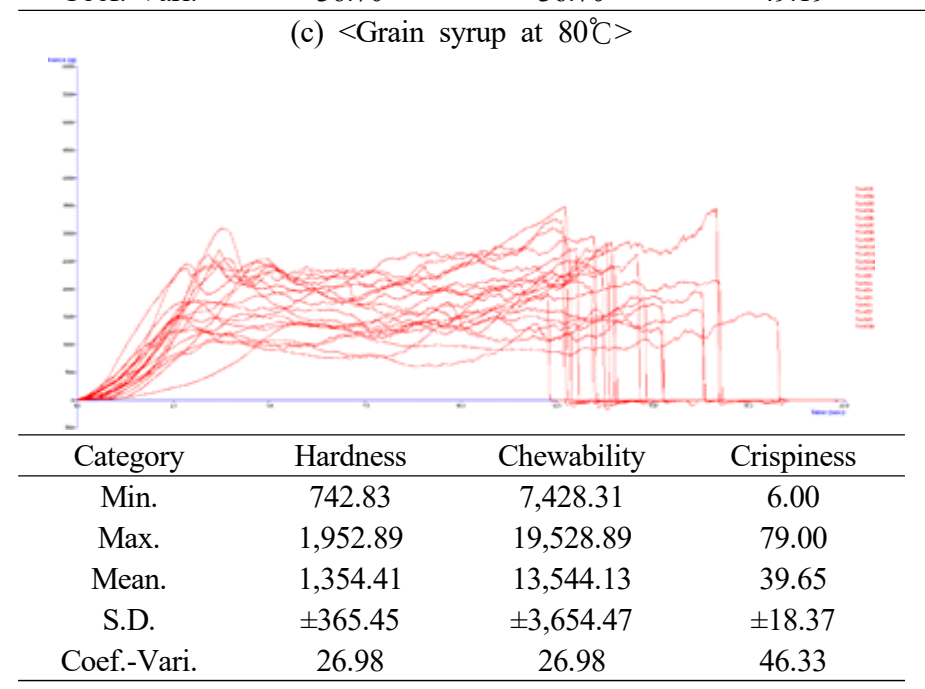

(d) $<$ Starch syrup at $80^{\circ} \mathrm{C}>$

(e) $<$ Grain syrup + starch syrup at $100^{\circ} \mathrm{C}>$

Fig. 10. Week 4 results at $4^{\circ} \mathrm{C}$ storage 


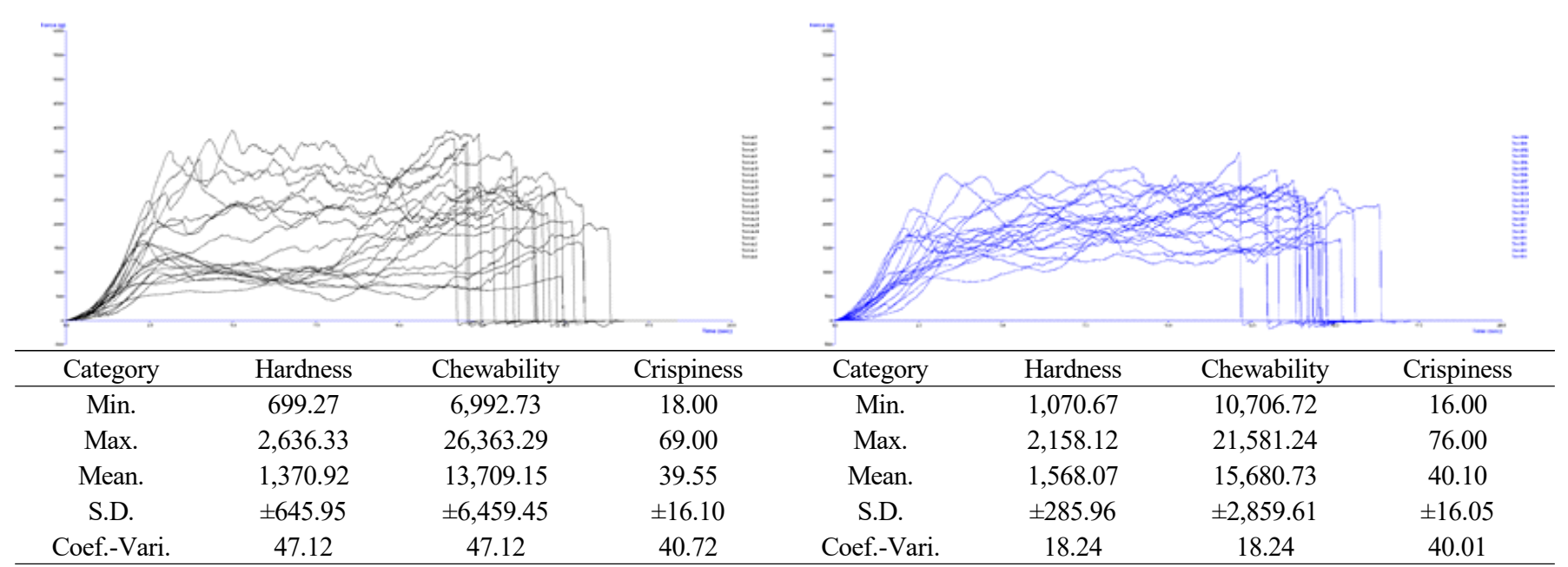

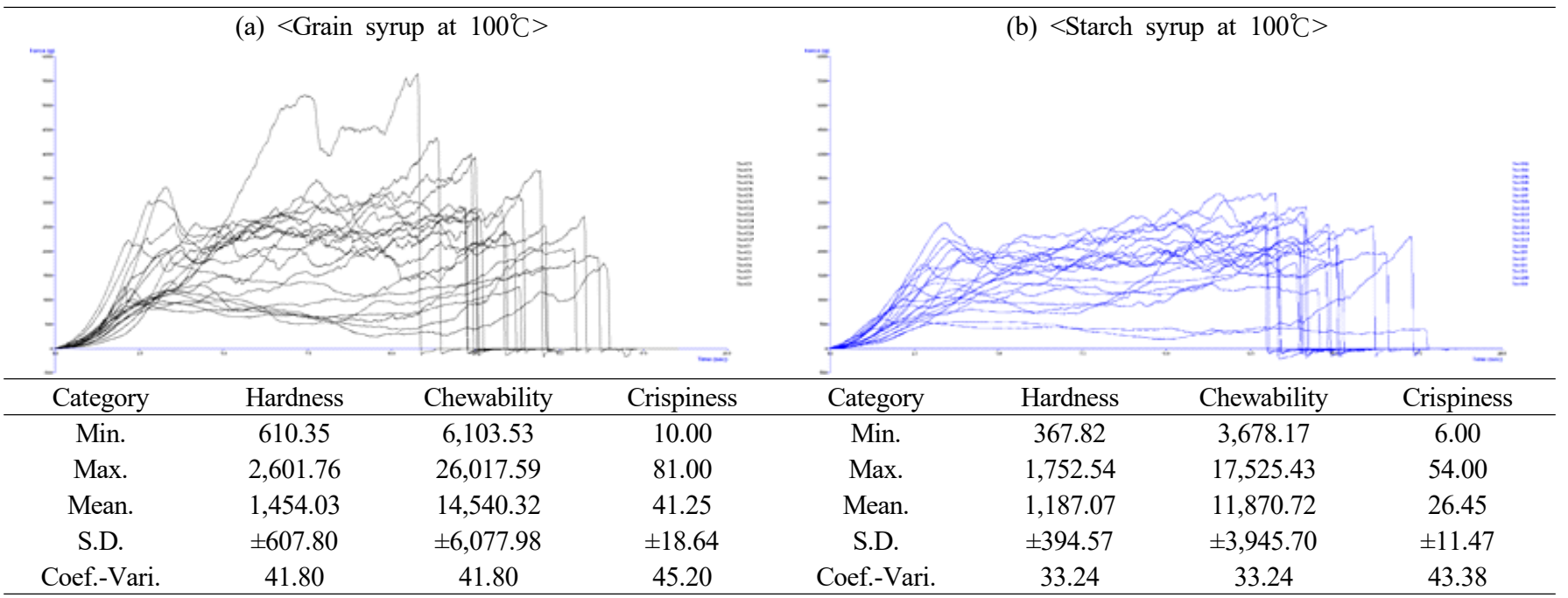

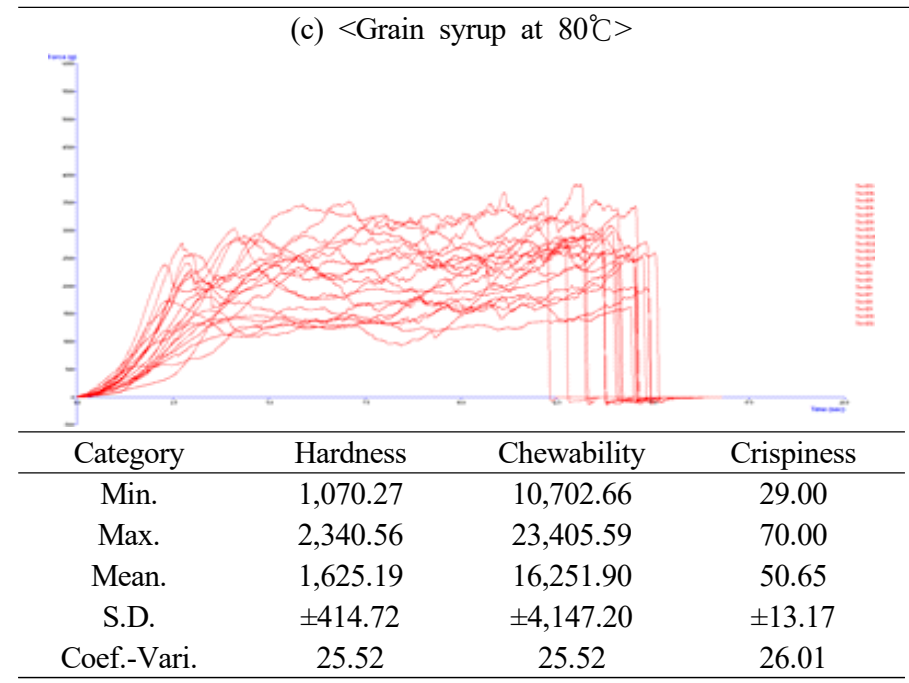

(d) $<$ Starch syrup at $80^{\circ} \mathrm{C}>$

(e) $<$ Grain syrup + starch syrup at $100^{\circ} \mathrm{C}>$

Fig. 11. Week 5 results at $4^{\circ} \mathrm{C}$ storage 


\section{Summary}

In this study, consumer preferences were evaluated according to the sugar types used to manufacture yugwa, changes in physical properties, and storage temperature. In conclusion, it was easier to maintain the quality according to the storage period, and consumer preference was higher whenusingfor mixed grain syrup and starch syrup or starch syrup alone than when grain syrup was used alone to manufacture yugwa. In addition, applying the sugar at $100^{\circ} \mathrm{C}$ maintains quality even though the storage period is increased, so it would be better to apply sugar at $100^{\circ} \mathrm{C}$ during yugwa manufacturing.

\section{Acknowledgments}

This study was supported by the 2020 Traditional Food Standardization Research Project (G02111000-01), and we extend our appreciation.

\section{References}

1. Choi SH, Cho YB. 2008. Effect of the commercialization factor of Korean sweets on brand image, recognition, and preference. Culin Sci Hosp Res 14:123-133.

2. Lee CH, Maeng Y-S. 1987. A literature review on traditional Korean cookies, Hankwa. J Korean Soc Food Cult 2:55-69.

3. Lee JY, Choi JS, Park YH, Lee HW. 2012. A survey on consumer perception of traditional Korean sweets. Korean Soc Community Life Sciences. Data collection of academic conferences of the Korean Society of Community Life Sciences 94.

4. National Agricultural Products Quality Management Agency. Standard standard for traditional food. 2020. 